\title{
Research and Scholarship Defined for portal: Libraries and the Academy
}

\author{
Charles B. Lowry
}

This essay serves to explain in some detail the definition of scholarship that the editorial board of portal: Libraries and the Academy applies when evaluating articles and assessing whether they are worthy of publication in our pages. It should be read in the larger context of the mission and purpose of portal that is defined in our front matter. I want to thank the board for its comments and formal adoption of this statement at our meeting during the 2004 annual conference of the American Library Association. At the same time, any failings of this essay are my own.

The main categories of scholarship that are the framework for our definition are the scholarships of discovery, integration, application, and teaching. This issue of portal contains a strong thematic core of articles about the utilization of problem-based learning for teaching information literacy. Thus, it focuses on the fourth type of scholarshipone that is often not taken as seriously as it should be. This thematic focus is also a departure for portal that we intend to formalize. It is the editorial board's intention that we take the opportunity that theme issues offer, from time to time, to have deeper, more extended, and critical discussions of important issues that are derived from research. In contrast, our editorial features will continue to emphasize opinion and commentary.

\section{Introduction}

Librarianship, the discipline we practice, arises from the professional training and the resultant work we do in specific institutional settings. At its base, librarianship is responsible for supplying the lifeblood of the rest of the academy-access to information for the advancement of knowledge, invention, and teaching. Since good librarianship is vital to the academic enterprise, it follows that advancing knowledge of the field of librarianship is vital to main- 
taining our ability to do so. It is important for portal referees to appreciate that what constitutes scholarship often comes from the context and experience of the work librarians do as individuals. Above all, librarianship is a practiced discipline.

Ernest Boyer, past president of the Carnegie Foundation for the Advancement of Teaching, provides four categories of research: "Specifically, we conclude that the work of the professoriate might be thought of as having four separate but overlapping functions. These are: the scholarship of discovery; the scholarship of integration; the scholarship of application; and the scholarship of teaching."1These categories are discussed in some detail below. Scholarship of discovery, so-called "pure and applied research," pursues new knowledge. Scholarship of integration synthesizes and interprets knowledge to provide perspective. Scholarship of application solves problems for a larger community using knowledge from one's particular field of expertise. Scholarship of teaching and learning contributes to knowledge about how people learn. Boyer asserts the central principle that:

At the research university, original research and publication should remain the basic expectation and be considered the key criteria by which the performance of most faculty will be assessed. Where else but in our major research universities-with their intellectual and physical resources and their tradition of rigorous and untrammeled inquiry — should the bulk of research in a free society be conducted and rewarded? ${ }^{2}$

He emphasizes that the scope of research (scholarship) necessary to encompass the variety and richness of disciplines requires an "enlarging the perspective" of what scholarship means in order to comprehend its variants, to assure that it strongly supports the core mission of the academy, and to effectively nurture the diversity of the scholarly enterprise. Much of this is useful when considering the research scholarship of our profession, and it certainly applies to all of higher education not just to the "research universities," as defined by the Carnegie Classification schema.

\section{The Scholarship of Discovery}

The scholarship of discovery, at its best, contributes not only to the stock of human knowledge but also to the intellectual climate of a college or university. Not just the outcomes, but also the process, and especially the passion, give meaning to the effort. The advancement of knowledge can generate an almost palpable excitement in the life of an educational institution. ... It is tied inextricably to the freedom to think freshly, to see propositions of every kind in ever-changing light. And it celebrates the special exhilaration that comes from a new idea. ${ }^{3}$

This is the most easily recognized form of scholarship, because in its final form it invariably appears in publication that falls within the traditional canon of refereed publication. However, even here the boundaries are becoming less defined as "publication on the Internet" emerges, and the academy struggles to extend to it the traditional "quality control" characteristic of print. Librarians, like teaching faculty, frequently, if not exclusively, publish scholarship of discovery in easily recognizable outlets. The challenge is not to limit the definition of scholarship exclusively to this form of research, thereby restricting portal consideration of other forms of scholarship. 


\section{The Scholarship of Integration}

In proposing the scholarship of integration, we underscore the need for scholars who give meaning to isolated facts, putting them in perspective. By integration, we mean making connections across the disciplines, placing the specialties in larger context, illuminating data in revealing way, often educating non-specialists, too. In calling for a scholarship of integration, what we mean is serious, disciplined work that seeks to interpret, draw together, and bring new insight to bear on original research.

The scholarship of integration is, of course, closely related to discovery. It involves first doing research at the boundaries where fields converge, and it reveals itself in what philosopher-physicist Michael Polanyi calls 'overlapping [academic] neighborhoods.' Such work is, in fact, increasingly important as traditional disciplinary categories prove confining, forcing new topologies of knowledge.

Scholarship of integration also means interpretation, fitting one's own research-or the research of others-into larger intellectual patterns. Such efforts are increasingly essential since specialization without broader perspective risks pedantry. The distinction we are drawing here between 'discovery' and 'integration' can best be understood, perhaps, by the question posed. Those engaged in discovery ask, 'What is to be known, what is yet to be found?' Those engaged in integration ask, 'What do the findings mean?' Is it possible to interpret what's been discovered in ways that provide a larger more comprehensive understanding? ${ }^{4}$

Unquestionably, librarianship has relied heavily on scholarship of integration to advance the knowledge of the discipline-drawing as it does from the literature of other disciplines such as management, organizational theory, computer science, pedagogy, and most explicitly the arts and science disciplines that undergird the subject expertise of many librarians. Much of this sort of scholarship appears in the published literature, but it is equally apparent in the working papers, technical reports, project briefings, and many other documents that are produced by librarians to accomplish the work of the library as an institution. The documentation of this scholarship in the past has often been disappearing "gray literature." Today, it is increasingly salient on library Web sites as examples of "best practices" that inform the whole community. When it illustrates an adopted practice-in one or multiple libraries-it shapes and contributes to the discipline. Much of it is worthy of formal publication.

\section{The Scholarship of Application}

The first two kinds of scholarship—discovery and integration of knowledge-reflect the investigative and synthesizing traditions of academic life. The third element, the application of knowledge, moves toward engagement as the scholar asks, 'How can knowledge be responsibly applied to consequential problems? How can it be helpful to individuals as well as institutions? And further, can social problems themselves define an agenda for a scholarly investigation?'

The scholarship of application, as we define it here, is not a one-way street. Indeed, the term itself may be misleading if it suggests that knowledge is first 'discovered' then 'applied.' The process we have in mind is far more dynamic. New intellectual understandings can arise out of the very act of application. ${ }^{5}$ 
This is the area in which librarians practicing librarianship often find themselves advancing knowledge. In librarianship such scholarship often works in tandem with scholarship of discovery and integration, as well. It is reflected in a variety of scholarly products that allow us to recognize this

Thus, scholarship of application helps advance practice and should be considered for publication in our pages, often as case studies. contribution-Web sites, software, exhibitions, bibliographies, and the like that help move the library enterprise forward. Thus, scholarship of application helps advance practice and should be considered for publication in our pages, often as case studies.

\section{The Scholarship of Teaching}

Finally, we come to the scholarship of teaching. The work of the professor becomes consequential only as it is understood by others. Yet, today, teaching is often viewed as a routine function, tacked on, something almost anyone can do. When defined as scholarship, however, teaching both educates and entices future scholars. Indeed, as Aristotle said, 'Teaching is the highest form of understanding.'

As a scholarly enterprise, teaching begins with what the teacher knows. Those who teach must, above all, be well informed, and steeped in the knowledge of their fields. Teaching can be well regarded only as professors are widely read and intellectually engaged. ${ }^{6}$

The scholarship of teaching is a "sub-discipline" for librarianship since, generally speaking, it is usually practiced by public service librarians working with teaching faculty to ensure the information literacy and competency of students in a discipline. For others, "training sessions" provide opportunities to teach that are vital to improving work processes and organizational development. Like faculty classroom teaching, that of librarians often calls for innovation and the development of new methods, as well as (increasingly) technology applications. This is a vital contribution when it happens. The scholarly byproducts are sometimes published in the usual way, but more often they are not-taking instead fixed form in software, Web sites, online bibliographies, among others.

\section{Assessment of Research Methods in Library/Information Science}

Another perspective that is useful in evaluating the research portal considers is the methodology used. Often when we assess the value of research, it is from this perspective. It is always possible that an evaluator may reject or diminish the importance of research simply because he or she does not appreciate/understand its methodological foundations. The following list of methods is largely drawn from work by Virgil L. P. Blake. ${ }^{7}$ However, the list does not comprehend all legitimate methodologies, just those most used in the discipline. It should be considered as background when reflecting on the value of research set in Boyer's larger framework. The methods identified by Blake are as follows (parenthetical scope notes are expanded from the original):

- Descriptive

- Case study 
- Bibliographic (e.g., essays and review articles)

- Historical/biographical

- Survey (questionnaires, interviews, unobtrusive observation, etc.)

- Bibliometric (including citation studies)

- Content analysis

- Modeling

- Experimental (generally pure or applied research intended to advance basic knowledge that does not have a practical application as an immediate objective)

- Quasi-experimental (generally applied research directed toward using knowledge from experimental research for practical or utilitarian purposes)

- Theory (generally used in one of several ways-discussion of theory to evaluate its efficacy for research, the development of new theoretical models/constructs that may be used as a basis for research experiments, or synthesizing theory from other disciplines for that purpose)

Finally, portal reviews must be rigorous. A significant part of scholarly and creative activity in librarianship may not be easy to assess, particularly if it is "applied." This means that the articles we publish will have present several important characteristics, and their absence is a measure of inadequacy. The scholarship:

1. must be unique, standing apart from other similar work as a new contribution that advances the knowledge of the field or provides a unique service or product;

2. must be needed-in demand in individual institutions or broadly required elsewhere by other libraries-having intrinsic value and utility;

3. must be used locally, and likely elsewhere, as an illustration of the value to the field of librarianship;

4. in sum, must not be trivial.

Charles B. Lowry is dean of University Libraries, University of Maryland, College Park, MD; he may be contacted via e-mail at clowry.umd.edu.

\section{Notes}

1. Ernest L. Boyer, Scholarship Reconsidered, Priorities of the Professoriate. Special Report (Princeton, NJ: Carnegie Foundation for the Advancement of Teaching, 1990), 16.

2. Ibid., 57.

3. Ibid., 17.

4. Ibid., 19-20.

5. Ibid., $21-2$.

6. Ibid., 23.

7. Virgil L.P. Blake, "Research Methods in LIS Dissertations," in Encyclopedia of Library and Information Science (New York: Marcel Dekker, Inc., 2003), 2513-23. 